\title{
ẢNH HƯởNG CỦA MộT SỐ NGUỒN ÁNH SÁNG NHÂN TẠO ĐẾN KHẢ NĂNG SINH TRỬ̛̉̉ VÀ PHÁT TRIỂN CỦA CÂY ĐİA LAN (CYMBIDIUM SPP.) VÀ CÂY HOA CÚC (CHRYSANTHEMUM SPP.)
}

\author{
Dương Tấn Nhựt", Lê Thị Phương Thảo, Trịnh Thị Hương, Nguyễn Bá Nam \\ Viện Nghiên cứu Khoa học Tây Nguyên, Viện Hàn lâm KHCNVN, Đà Lạt, Lâm Đồng \\ "Email: duongtannnhut@gmail.com
}

Đến Tòa soạn: 8/5/2014; Chấp nhận đăng: 22/12/2014

\begin{abstract}
TÓM TẮT
Ánh sáng là nguồn năng lượng chính trong quang hợp của cây trồng. Tuy nhiên, ánh sáng đèn huỳnh quang là nguồn ánh sáng chính trong các phòng nuôi cấy mô tế bào thực vật hiện tại; do đó giá thành của cây trồng cao vì nó đã tiêu thụ một lượng lớn điện năng. Vì vậy, trong nghiên cứu này, chúng tôi đánh giá ảnh hưởng của việc tiết kiệm năng lượng ánh sáng (đèn compact huỳnh quang) lên khả năng tăng trưởng và phát triển của Chrysanthemum and Cymbidium để tìm ra hệ thống tiết kiệm năng lượng thay thế cho hệ thống chiếu sáng truyền thống. Kết quả thu được cho thấy đèn có chứa nhiều tia đỏ (đèn compact $1 \mathrm{U}$ đỏ, đèn compact $1 \mathrm{U}$ trắng và đèn compact $3 \mathrm{U}$ ) phù hợp cho sự phát triển của cây hơn đèn chứa nhiều tia xanh (đèn compact $1 \mathrm{U}$ màu xanh lá cây). Trong đó, đèn compact $3 \mathrm{U}$ phù hợp cho sự hình thành chồi của Cúc cũng như hệ số nhân PLB và khối lượng tươi của PLB Địa lan. Đèn compact $1 \mathrm{U}$ trắng phù hợp cho sự hình thành rễ của cả cúc và địa lan cũng như sự tăng trưởng của cây con khi trồng ngoài vườn ươm. Vì vậy, thay vì sử dụng hệ thống chiếu sáng truyền thống (đèn neon), chúng ta nên sử dụng đèn compact, không chỉ tiết kiệm năng lượng mà còn thúc đẩy sự tăng trưởng của cây trồng tốt hơn.
\end{abstract}

Tù khóa: ánh sáng, cúc, compact, Địa lan, sinh trưởng.

\section{GIỚI THIỆU}

Vi nhân giống thực vật hiện nay đang được thực hiện tại rất nhiều các vườn ươm cây và phòng thí nghiệm công nghệ sinh học lớn nhỏ trên thế giới. Ở các phòng nuôi cấy mô thương mại này, nguồn ánh sáng bức xạ được dùng phổ biến nhất cho vi nhân giống là đèn huỳnh quang. Mặc dù một số đèn huỳnh quang thích hợp cho sự tăng trưởng của thực vật nhưng tất cả đèn huỳnh quang này đều tỏa nhiệt, do đó phải tiêu tốn thêm một phần điện năng để làm giảm nhiệt độ do các đèn gây ra. Hiện nay, điện năng đang là vấn đề hết sức bức thiết, sự thiếu hụt điện năng ảnh hưởng rất lớn đển đời sống con người. Trước tình hình đó, sự phát triển nguồn bức xạ hiệu quả hơn sử dụng trong các phòng nuôi cấy mô sẽ tiết kiệm được nguồn điện năng đồng thời mang lại nguồn lợi đáng kể để giảm chi phí sản xuất trong vi nhân giống [1]. Chính vì vậy, nghiên cứu đang được quan tâm trong lĩnh vực ánh sáng nhân tạo cho cây trồng là tìm được 
nguồn ánh sáng có chất lượng ánh sáng cao, tiêu thụ điện năng ít. Nhiều loại đèn khác nhau đã được tập trung nghiên cứu với nhiều kết quả khả quan [2,3,4]. Tuy nhiên, loại đèn huỳnh quang vẫn đang được sử dụng phổ biến nhất. Đèn huỳnh quang có hai dạng là đèn huỳnh quang ống phẳng và đèn huỳnh quang compact. Trước đây đèn compact ít được sử dụng trong nuôi cấy mô thực vật, nhưng gần đây đã có nhiều nghiên cứu tập trung vào sử dụng loại đèn này. Nguyên nhân là do nó có tuổi thọ cao và tiết kiệm được điện năng. Một số nghiên cứu đã ứng dụng thành công loại bóng đèn này trong vi nhân giống với một số đối tượng như: Hoa chuông, Khoai tây [1], Dâu tây, Địa lan, Lily [5].

Thực vật là loài rất nhạy cảm với ánh sáng, mỗi loài sẽ có một phổ ánh sáng hấp thụ khác nhau. Vì vậy trong nghiên cứu này, chúng tôi trình bày ảnh hưởng của một số nguồn ánh sáng nhân tạo (đèn neon, đèn compact $1 \mathrm{U}$ xanh lá cây, đèn compact $1 \mathrm{U}$ đỏ, đèn compact $1 \mathrm{U}$ trắng, đèn compact $3 \mathrm{U}$ ) lên khả năng sinh trưởng và phát triển của cây Địa lan (Cymbidium spp.) và cây hoa Cúc (Chrysanthemum spp.).

\section{VẬT LIỆU VÀ PHƯƠNG PHÁP}

\subsection{Hệ thống ánh sáng}

Đèn chiếu sáng được sử dụng trong thí nghiệm là các loại đèn tiết kiệm điện năng có chất lượng cao do công ty Bóng đèn phích nước Rạng Đông sản xuất, bao gồm: đèn neon $(\mathrm{N})$ (Hình 1a), đèn compact $3 \mathrm{U}(3 \mathrm{U})$ (Hình $1 \mathrm{~b}$ ), đèn compact $1 \mathrm{U}$ màu xanh lá cây $(\mathrm{GU})$ (Hình $1 \mathrm{c})$, đèn compact $1 \mathrm{U}$ đỏ $(\mathrm{RU})$ (Hình $1 \mathrm{~d})$, đèn compact $1 \mathrm{U}$ trắng $(\mathrm{WU})$ (Hình 1e).

\subsection{Nguồn mẫu thực vật nuôi cấy}

\subsubsection{Mẫu cấy hoa Cúc}

Các đốt thân cây Cúc in vitro có chiều cao $1-1,5 \mathrm{~cm}$ được dùng làm nguyên liệu cho thí nghiệm khảo sát khả năng nhân chồi.

Các chồi cây Cúc in vitro có chiều cao $3-4 \mathrm{~cm}$ được dùng làm nguyên liệu cho thí nghiệm khảo sát khả năng hình thành rễ.

Các đốt thân và các chồi Cúc được cấy lên môi trường thạch tương ứng và đặt dưới các điều kiện ánh sáng khác nhau để khảo sát ảnh hưởng của các nguồn ánh sáng này tới sự sinh trưởng, phát triển của cây hoa Cúc.

\subsubsection{Mẫu cấy Địa lan}

Các PLB (Protocorm-like body) Địa lan giống "Tím hột" in vitro có khối lượng tươi trung bình khoảng $75 \mathrm{mg}$ được cắt đôi theo chiều dọc sau đó đem nuôi cấy trên môi trường nhân PLB và được đặt dưới các điều kiện chiếu sáng khác nhau để khảo sát ảnh hưởng của các nguồn ánh sáng này tới khả năng tăng trưởng của PLB.

Các chồi Địa lan thu được sau đó sẽ được chuyển vào môi trường ra rễ và đặt dưới các điều kiện ánh sáng khác nhau để khảo sát ảnh hưởng của các nguồn sáng này tới khả năng hình thành cây con hoàn chỉnh.

\subsection{Môi trường nuôi cấy}


Môi trường nhân chồi cây hoa Cúc: môi trường MS [6] có bổ sung $0,5 \mathrm{mg} / \mathrm{l} \mathrm{BA}, 0,2 \mathrm{mg} / \mathrm{l}$ NAA, $20 \mathrm{~g} / 1$ sucrose và $8 \mathrm{~g} / \mathrm{l}$ agar, $\mathrm{pH}=5,8$.

Môi trường ra rễ cây hoa Cúc: môi trường 1/2MS có bổ sung 0,4 mg/l NAA, 20 g/l sucrose, $0,2 \mathrm{mg} / \mathrm{l}$ than hoạt tính và $8 \mathrm{~g} / \mathrm{l}$ agar, $\mathrm{pH}=5,8$.

Môi trường nhân PLB Địa lan: môi trường MS có bổ sung $2 \mathrm{mg} / \mathrm{l} \mathrm{BA}, 0,5 \mathrm{mg} / \mathrm{l} \mathrm{NAA}$, $30 \mathrm{~g} / \mathrm{l}$ sucrose, $20 \%$ (v/v) nước dừa, $1 \mathrm{~g} / \mathrm{l}$ than hoạt tính và $8 \mathrm{~g} / \mathrm{l}$ agar, $\mathrm{pH}=5,8$.

Môi trường ra rễ Địa lan: môi trường MS có bổ sung 0,5 mg/l BA, 0,5 mg/l NAA, 25 g/l sucrose, $10 \%(\mathrm{v} / \mathrm{v})$ nước dừa, $1 \mathrm{~g} / \mathrm{l}$ than hoạt tính và $8 \mathrm{~g} / \mathrm{l}$ agar, $\mathrm{pH}=5,8$.

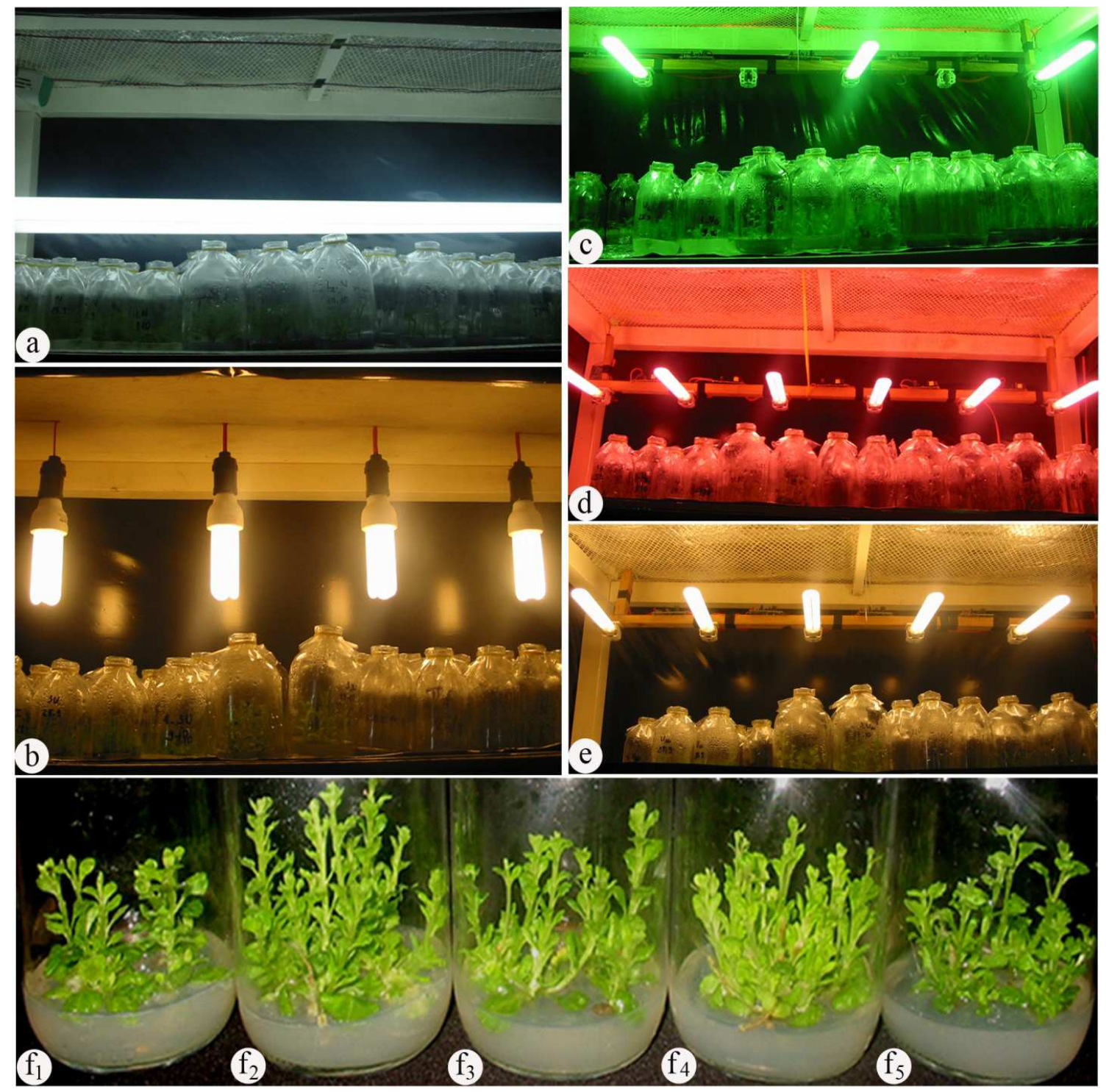

Hình 1. Ảnh hưởng của một số nguồn ánh sáng nhân tạo đến khả năng sinh trưởng và phát triển của cây Địa lan và cây hoa Cúc. a. Đèn neon $(\mathrm{N})$; b. Đèn compact $3 \mathrm{U}(3 \mathrm{U})$; c. Đèn compact $1 \mathrm{U}$ màu xanh lá cây $(\mathrm{GU}) ; \mathbf{d}$. Đèn compact $1 \mathrm{U}$ màu đỏ $(\mathrm{RU})$; $\mathbf{e}$. Đèn compact $1 \mathrm{U}$ màu trắng $(\mathrm{WU}) ; \mathbf{f}_{\mathbf{1}}, \mathbf{f}_{\mathbf{2}}, \mathbf{f}_{3}, \mathbf{f}_{4}, \mathbf{f}_{5}$. Sự phát triển của cây hoa Cúc dưới các đèn $\mathrm{GU}, \mathrm{RU}, \mathrm{WU}, 3 \mathrm{U}, \mathrm{N}$ (theo thứ tự từ trái qua phải). 


\section{4. Điều kiện thí nghiệm}

Tất cả các thí nhiệm được tiến hành ở các điều kiện: thời gian chiếu sáng là 16 giờ/ngày; cường độ chiếu sáng là 2.500 lux; nhiệt độ phòng sáng $25 \pm 2{ }^{\circ} \mathrm{C}$; ẩm độ trung bình $75-80 \%$.

Các số liệu thu được trong nghiên cứu này được xử lí bằng phần mềm SPSS 16.0 với phép thử Duncan $\alpha=0,05$ [7].

\section{KẾT QUẢ VÀ THẢO LUẬN}

\section{1. Ảnh hưởng của chất lượng ánh sáng từ các loại đèn khác nhau lên sự hình thành chồi của cây Cúc và sự hình thành PLB của cây Địa lan}

Bảng 1.1. Ảnh hưởng của các nguồn khác ánh sáng khác nhau lên sự hình thành chồi Cúc.

\begin{tabular}{|c|c|c|c|c|}
\hline \multicolumn{2}{|c|}{ Chỉ tiêu theo dõi } & $\begin{array}{c}\text { Chiều cao cây } \\
(\mathbf{c m})\end{array}$ & Số chồi & $\begin{array}{c}\text { Khối lượng tươi } \\
\text { chồi (mg) }\end{array}$ \\
\hline \multirow{3}{*}{ Nguồn sáng } & $\mathrm{N}$ & $4,2 \mathrm{ef}$ & $2,6 \mathrm{e}$ & $110,8 \mathrm{bc}$ \\
\cline { 2 - 5 } & $\mathrm{GU}$ & $3,9 \mathrm{f} *$ & $2,8 \mathrm{de}$ & $82,9 \mathrm{de}$ \\
\cline { 2 - 5 } & $\mathrm{RU}$ & $4,6 \mathrm{~d}$ & $4,0 \mathrm{ab}$ & $78,2 \mathrm{e}$ \\
\cline { 2 - 5 } & $\mathrm{WU}$ & $5,1 \mathrm{ab}$ & $3,9 \mathrm{bc}$ & $95,1 \mathrm{~cd}$ \\
\cline { 2 - 5 } & $3 \mathrm{U}$ & $4,9 \mathrm{bc}$ & $3,4 \mathrm{~cd}$ & $121,2 \mathrm{ab}$ \\
\hline
\end{tabular}

Ghi chú: *Các chữ cái khác nhau $(\mathrm{a}, \mathrm{b} . .$.$) trong cùng một cột biểu thị sự khác biệt có ý nghĩa thống kê ở$ $\alpha=0,05$ (Duncan's test).

Đối với cây Cúc, các kết quả cho thấy chất lượng ánh sáng có ảnh hưởng đến đốt thân Cúc. Đốt thân Cúc đặt dưới các đèn $\mathrm{N}$ và đèn $\mathrm{GU}$ không nhận thấy có sự khác biệt nhiều về chiều cao cây và số chồi. Dưới các đèn RU, WU và $3 U$ chiều cao chồi và số chồi thu được cao hơn hẳn so với các đèn khác. Điều này có thể giải thích là do các loại đèn $R U$, WU và $3 U$ có thành phần ánh sáng đỏ nhiều, còn đèn $\mathrm{N}$ và đèn $\mathrm{GU}$ có thành phần ánh sáng chủ yếu là xanh lá cây nên bị cây phản xạ lại, do đó, lượng ánh sáng mà cây hấp thụ không nhiều. Do đó, khi xét về hệ số nhân chồi, chúng tôi nhận thấy 3 loại đèn RU, WU và $3 U$ có hiệu quả nhất. Chiều cao cây thu được ở đèn WU đạt cao hơn so với đèn $R U$ và $3 U$, nhưng số chồi thu được ở đèn RU lại cao hơn so với 2 loại đèn $\mathrm{WU}$ và $3 \mathrm{U}$. Trong khi đó, khối lượng tươi thu được ở 3 loại đèn này lại có sự khác biệt lớn. Khối lượng tươi đạt cao nhất là ở đèn $3 U$. Từ các kết quả thu được có thể thấy rằng, ở đèn $3 U$ mặc dù chiều cao cây và số chồi thu được là không cao nhất, nhưng khối lượng tươi của chồi thu được cao hơn đáng kể so với các loại đèn khác. Điều này có nghĩa là ở đèn $3 U$ thì các chồi Cúc thu được có chất lượng cao nhất (Bảng 1.1). Ở đèn $\mathrm{N}$, khối lượng tươi chồi thu được cũng khá cao, tuy nhiên, số lượng chồi thu được lại thấp, do đó hiệu quả nhân giống không cao. Từ các kết quả thu được ở tất cả các chỉ tiêu, ta nhận thấy các mẫu cấy đặt dưới đèn $3 \mathrm{U}$ có sự phát triển tốt nhất (Hình 1f).

Trong thí nghiệm trên đối tượng cây hoa Cúc, ở các đèn chứa nhiều ánh sáng xanh (đèn $\mathrm{N}$ và đèn $\mathrm{GU}$ ) thì sự phát triển của chồi thấp. Điều này là do ánh sáng xanh dương kìm hãm sự phát triển của thực vật, trong khi đó ánh sáng xanh lá cây thì thực vật không hấp thụ. Các kết quả mà chúng tôi thu được cũng hoàn toàn tương tự với các nghiên cứu của Moreira da Silva và 
Debergh (1997), Schuerger và cộng sự (1997), Mortensen và Stromme (1987) khi nghiên cứu trên các đối tượng cây A. vidalii (Wats.) Feer, cây Tiêu và nhiều cây trồng trong nhà kính; các tác giả này cũng nhận thấy tác dụng ức chế sự phát triển chồi của những loài cây này khi trồng dưới điều kiện ánh sáng xanh đơn sắc $[8,9,10]$.

Bảng 1.2. Ảnh hưởng của các nguồn ánh sáng khác nhau lên sự hình thành PLB Địa lan.

\begin{tabular}{|c|c|c|c|c|}
\hline \multicolumn{2}{|c|}{ Chỉ tiêu theo dõi } & Số lượng PLB & Số chồi & $\begin{array}{c}\text { Khối lượng tươi } \\
\text { PLB (mg) }\end{array}$ \\
\hline \multirow{4}{*}{ Nguồn sáng } & $\mathrm{N}$ & $5,3 \mathrm{e}^{*}$ & $0,3 \mathrm{c}$ & $90,1 \mathrm{e}$ \\
\cline { 2 - 5 } & $\mathrm{GU}$ & $8,0 \mathrm{de}$ & $0,3 \mathrm{c}$ & $104,5 \mathrm{de}$ \\
\cline { 2 - 5 } & $\mathrm{RU}$ & $10,3 \mathrm{cde}$ & $0,4 \mathrm{bc}$ & $197,6 \mathrm{abc}$ \\
\cline { 2 - 5 } & $\mathrm{WU}$ & $14,1 \mathrm{bc}$ & $0,8 \mathrm{abc}$ & $171,7 \mathrm{bcd}$ \\
\cline { 2 - 5 } & $3 \mathrm{U}$ & $19,1 \mathrm{ab}$ & $0,8 \mathrm{abc}$ & $144,7 \mathrm{cde}$ \\
\hline
\end{tabular}

Ghi chú: *Các chữ cái khác nhau $(\mathrm{a}, \mathrm{b} . .$.$) trong cùng một cột biểu thị sự khác biệt có ý nghĩa thống kê ở$ $\alpha=0,05$ (Duncan's test).

Đối với Địa lan, các loại đèn cung cấp nhiều ánh sáng đỏ (RU, WU và $3 U$ ) đều cho số lượng PLB tương đối cao và khi nuôi cấy dưới đèn $3 \mathrm{U}$ thì sự hình thành PLB đạt được kết quả tốt hơn so với các loại đèn còn lại. Tuy nhiên, số lượng chồi hình thành khi nuôi cấy dưới các loại đèn này không có sự khác biệt đáng kể về mặt thống kê; số lượng chồi thu được tốt hơn ở điều kiện chiếu sáng đèn $\mathrm{WU}$ và $3 \mathrm{U}$. Kết quả khi xét về chỉ tiêu khối lượng tươi của PLB cho thấy, không có sự khác biệt nhiều giữa đèn $3 \mathrm{U}$ và đèn $\mathrm{GU}$ so với đèn $\mathrm{N}$. Trong khi đó, khối lượng tươi của PLB ở đèn RU và WU cao hơn nhiều so với đèn neon, và đạt kết quả tốt hơn là ở đèn $R U$. Tuy nhiên, khi xem xét tất cả các chỉ tiêu, đèn $W U$ và $3 U$ thích hợp nhất cho sự nhân PLB do tạo được nhiều PLB mới với khối lượng tươi của PLB khá cao (Bảng 1.2).

Từ các kết quả thu được ta thấy, ánh sáng đỏ giúp thúc đẩy sự phát triển của PLB Địa lan, còn ánh sáng xanh thì không mang lại hiệu quả này. Ánh sáng đỏ cũng kích thích sự hình thành chồi (ở đèn $\mathrm{WU}$ và $3 \mathrm{U}$ ), tuy nhiên không cao. Như vậy, trong các loại đèn được khảo sát thì đèn WU và $3 U$ phù hợp nhất cho sự hình thành và phát triển của PLB.

\section{2. Ảnh hưởng của chất lượng ánh sáng từ các loại đèn khác nhau lên sự hình thành rễ của chồi Cúc và Địa lan}

Kết quả thu được cho thấy, không có sự khác biệt rõ rệt về chiều cao cây, số rễ và khối lượng tươi của cây giữa đèn $\mathrm{GU}$ và đèn $\mathrm{N}$. Chiều dài rễ் thu được ở đèn $\mathrm{GU}$ thấp hơn hẳn so với đèn $\mathrm{N}$. Ở đèn $3 \mathrm{U}$, số lượng rễ và chiều dài rễ thu được khi nuôi cấy chồi Cúc đều cao hơn so với đèn $\mathrm{N}$, nhưng chiều cao cây và khối lượng tươi của cây thì không có sự khác biệt rõ rệt so với đèn $\mathrm{N}$. Ở hai loại đèn còn lại là $\mathrm{RU}$ và $\mathrm{WU}$, các chỉ tiêu thu được đều cao hơn hẳn so với đèn $\mathrm{N}$, ngoại trừ chỉ tiêu chiều dài rễ thu được ở đèn RU là không có sự khác biệt rõ rệt so với đèn $\mathrm{N}$. Trong đó, kết quả thu được khi mẫu nuôi cấy dưới đèn WU là tốt hơn so với các loại đèn khác về tất cả các chỉ tiêu (Bảng 2.1). 
Nhìn chung, sự phát triển của chồi Cúc in vitro dưới các đèn compact cao hơn so với đèn neon. Loại đèn compact thích hợp nhất cho sự phát triển của chồi Cúc thành cây con hoàn chỉnh là đèn WU.

Bảng 2.1. Ảnh hưởng của các nguồn khác ánh sáng khác nhau lên sự hình thành rễ của cây Cúc.

\begin{tabular}{|c|c|c|c|c|c|}
\hline \multicolumn{2}{|c|}{ Chỉ tiêu theo dõi } & $\begin{array}{c}\text { Chiều cao } \\
\text { cây }(\mathbf{c m})\end{array}$ & Số rễ & $\begin{array}{c}\text { Chiều dài rễ } \\
(\mathbf{m m})\end{array}$ & $\begin{array}{c}\text { Khối lượng } \\
\text { tươi của cây } \\
(\mathbf{m g})\end{array}$ \\
\hline \multirow{3}{*}{ Nguồn sáng } & $\mathrm{N}$ & $5,7 \mathrm{e}^{*}$ & $6,8 \mathrm{e}$ & $23,3 \mathrm{e}$ & $212,1 \mathrm{f}$ \\
\cline { 2 - 6 } & $\mathrm{GU}$ & $5,9 \mathrm{de}$ & $7,1 \mathrm{de}$ & $14,4 \mathrm{f}$ & $236,2 \mathrm{ef}$ \\
\cline { 2 - 6 } & $\mathrm{RU}$ & $6,7 \mathrm{bc}$ & $9,3 \mathrm{bc}$ & $23,7 \mathrm{de}$ & $345,6 \mathrm{bcd}$ \\
\cline { 2 - 6 } & $\mathrm{WU}$ & $7,1 \mathrm{ab}$ & $9,5 \mathrm{ab}$ & $31,3 \mathrm{a}$ & $365,1 \mathrm{abcd}$ \\
\cline { 2 - 6 } & $3 \mathrm{U}$ & $6,1 \mathrm{cde}$ & $8,8 \mathrm{~cd}$ & $24,4 \mathrm{bcd}$ & $285,6 \mathrm{def}$ \\
\hline
\end{tabular}

Ghi chú: *Các chữ cái khác nhau (a, b...) trong cùng một cột biểu thị sự khác biệt có ý nghĩa thống kê ở $\alpha=0,05$ (Duncan's test).

Bảng 2.2. Ảnh hưởng của các nguồn ánh sáng khác nhau lên sự hình thành rễ của Địa lan.

\begin{tabular}{|c|c|c|c|c|c|c|}
\hline \multicolumn{2}{|c|}{ Chỉ tiêu theo dõi } & $\begin{array}{c}\text { Chiều dài } \\
\text { lá }(\mathbf{c m})\end{array}$ & $\begin{array}{c}\text { Chiều } \\
\text { rộng lá } \\
\text { (mm) }\end{array}$ & Số rễ & $\begin{array}{c}\text { Chiều dài } \\
\text { rễ (mm) }\end{array}$ & $\begin{array}{c}\text { Khối } \\
\text { lượng tươi } \\
\text { cây (mg) }\end{array}$ \\
\hline \multirow{4}{*}{$\begin{array}{c}\text { Nguồn } \\
\text { sáng }\end{array}$} & $\mathrm{N}$ & $7,0 \mathrm{~d}^{*}$ & $4,2 \mathrm{~d}$ & $2 \mathrm{bcd}$ & $15,0 \mathrm{bcd}$ & $488,2 \mathrm{f}$ \\
\cline { 2 - 7 } & $\mathrm{GU}$ & $8,0 \mathrm{bc}$ & $4,3 \mathrm{~cd}$ & $1,4 \mathrm{e}$ & $14,4 \mathrm{~d}$ & $555,4 \mathrm{ef}$ \\
\cline { 2 - 7 } & $\mathrm{RU}$ & $8,2 \mathrm{ab}$ & $4,7 \mathrm{bcd}$ & $1,9 \mathrm{~cd}$ & $17,6 \mathrm{abcd}$ & $636,9 \mathrm{bcde}$ \\
\cline { 2 - 8 } & $\mathrm{WU}$ & $8,0 \mathrm{bc}$ & $5,1 \mathrm{ab}$ & $2,1 \mathrm{abcd}$ & $17,5 \mathrm{abcd}$ & $772,6 \mathrm{a}$ \\
\cline { 2 - 8 } & $3 \mathrm{U}$ & $7,3 \mathrm{~cd}$ & $4,3 \mathrm{~cd}$ & $1,8 \mathrm{de}$ & $14,6 \mathrm{~cd}$ & $562,9 \mathrm{cdef}$ \\
\hline
\end{tabular}

Ghi chú: *Các chữ cái khác nhau (a, b...) trong cùng một cột biểu thị sự khác biệt có ý nghĩa thống kê ở $\alpha=0,05$ (Duncan's test).

Kết quả thu được ở đối tượng cây Địa Lan cho thấy, không có sự khác biệt về chiều dài rễ giữa tất cả các loại đèn compact so với đèn neon. Số lượng rễ thu được thấp nhất ở đèn $\mathrm{GU}$; ở đèn $\mathrm{WU}, 3 \mathrm{U}$ và $\mathrm{RU}$ không có sự khác biệt rõ rệt về chỉ tiêu này so với đèn $\mathrm{N}$. Như vậy, chất lượng ánh sáng của các loại đèn được sử dụng trong thí nghiệm này không ảnh hưởng đến sự ra rễ của Địa lan, mà chỉ ảnh hưởng đến sự phát triển của lá và khối lượng tươi của cây. Chiều rộng lá thu được ở đèn WU là tốt hơn, còn các loại đèn compact còn lại không có sự khác biệt so với đèn neon. Mặc dù, chiều dài lá đạt kết quả tốt ở đèn $\mathrm{RU}$ và cao hơn hẳn so với đèn $\mathrm{N}$, nhưng không có sự khác biệt rõ rệt giữa đèn $R U$ với hai đèn $W U$ và $G U$. Khối lượng tươi của cây thu được cao nhất ở đèn $\mathrm{WU}$ và cao hơn nhiều so với đèn $\mathrm{N}$ (Bảng 2.2).

Như vậy, khi xem xét tất cả các chỉ tiêu thì đèn WU cho cây có chất lượng tốt nhất nên thích hợp cho giai đoạn cây Địa lan ra rễ. 


\section{3. Ảnh hưởng của chất lượng ánh sáng từ các loại đèn khác nhau xử lí trong giai đoạn in vitro lên sự phát triển, phát sinh hình thái của cây Cúc và cây Địa lan ngoài vườn ươm}

Bảng 3.1. Ảnh hưởng của các nguồn ánh sáng khác nhau xử lí trong giai đoạn in vitro lên sự phát triển, phát sinh hình thái của cây Cúc ngoài vườn ươm.

\begin{tabular}{|c|c|c|c|c|c|}
\hline \multicolumn{2}{|c|}{ Chỉ tiêu theo dõi } & $\begin{array}{c}\text { Chiều cao } \\
\text { cây }(\mathbf{c m})\end{array}$ & Số lá & Số rễ̂ & $\begin{array}{c}\text { Chiều dài rê̂ } \\
\text { (cm) }\end{array}$ \\
\hline \multirow{4}{*}{ Nguồn sáng } & $\mathrm{N}$ & $10,2 \mathrm{~cd}$ & $19,6 \mathrm{bcde}$ & $13,8 \mathrm{de}$ & $7,3 \mathrm{~cd}$ \\
\cline { 2 - 6 } & $\mathrm{GU}$ & $9,6 \mathrm{~d}^{*}$ & $18,2 \mathrm{e}$ & $12,2 \mathrm{e}$ & $5,9 \mathrm{~d}$ \\
\cline { 2 - 6 } & $\mathrm{RU}$ & $11,4 \mathrm{ab}$ & $20,3 \mathrm{abcde}$ & $14,3 \mathrm{abcde}$ & $9,2 \mathrm{ab}$ \\
\cline { 2 - 6 } & $\mathrm{WU}$ & $11,4 \mathrm{ab}$ & $18,6 \mathrm{de}$ & $14,0 \mathrm{bcde}$ & $8,0 \mathrm{bc}$ \\
\cline { 2 - 6 } & $3 \mathrm{U}$ & $11,1 \mathrm{bc}$ & $19,3 \mathrm{cde}$ & $13,9 \mathrm{cde}$ & $8,0 \mathrm{bc}$ \\
\hline
\end{tabular}

Ghi chú: *Các chữ cái khác nhau $(\mathrm{a}, \mathrm{b} . .$.$) trong cùng một cột biểu thị sự khác biệt có ý nghĩa thống kê ở$ $\alpha=0,05$ (Duncan's test).

Kết quả thu được cho thấy số lá, số rễ giữa các đèn không có sự chênh lệch nhiều, chứng tỏ việc xử lí các nguồn ánh sáng khác nhau trong giai đoạn nuôi cấy in vitro không ảnh hưởng tới hai chỉ tiêu này của cây Cúc. Chiều cao cây đạt kết quả tốt hơn các nghiệm thức khác khi cây được xử lí với đèn RU và đèn WU. Kết quả này cũng phù hợp với kết quả thu được ở thí nghiệm ảnh hưởng của ánh sáng đối với ra rễ của chồi Cúc, tuy nhiên, sự chênh lệch này không nhiều. Chiều dài rễ khi nuôi cấy dưới đèn RU cho kết quả tốt hơn hẳn, trong khi ở thí nghiệm 2 là ở đèn WU; tuy nhiên, trong thí nghiệm này khi xét về mức độ tin cậy xử lí thống kê thì chiều dài rễ giữa đèn $R U$ và đèn WU là như nhau, do đó, ta có thể xem như không có sự chênh lệch về chiều dài rễ giữa hai loại đèn này. Vì vậy, Cúc đặt dưới đèn WU trong giai đoạn in vitro là thích hợp nhất cho cả giai đoạn nhân giống in vitro và giai đoạn ex vitro (Bảng 3.1).

Bảng 3.2. Ảnh hưởng của các nguồn ánh sáng khác nhau xử lí trong giai đoạn in vitro lên sự phát triển, phát sinh hình thái của cây Địa lan ngoài vườn ươm.

\begin{tabular}{|c|c|c|c|c|c|}
\hline \multicolumn{2}{|c|}{ Chỉ tiêu theo dõi } & $\begin{array}{c}\text { Chiều cao } \\
\text { cây }(\mathbf{c m})\end{array}$ & Số lá & Số rễ & $\begin{array}{c}\text { Chiều dài rễ } \\
(\mathbf{m m})\end{array}$ \\
\hline \multirow{4}{*}{ Nguồn sáng } & $\mathrm{N}$ & $8,1 \mathrm{e}^{*}$ & $4,0 \mathrm{bc}$ & $2,3 \mathrm{bcd}$ & $19,8 \mathrm{bc}$ \\
\cline { 2 - 6 } & $\mathrm{GU}$ & $8,6 \mathrm{bcde}$ & $4,3 \mathrm{abc}$ & $1,8 \mathrm{e}$ & $20,1 \mathrm{bc}$ \\
\cline { 2 - 6 } & $\mathrm{RU}$ & $8,4 \mathrm{cde}$ & $3,9 \mathrm{c}$ & $1,9 \mathrm{de}$ & $21,5 \mathrm{abc}$ \\
\cline { 2 - 6 } & $\mathrm{WU}$ & $9,2 \mathrm{abcd}$ & $4,0 \mathrm{bc}$ & $4,3 \mathrm{a}$ & $22,1 \mathrm{abc}$ \\
\cline { 2 - 6 } & $3 \mathrm{U}$ & $8,2 \mathrm{de}$ & $4,3 \mathrm{abc}$ & $2,0 \mathrm{cde}$ & $18 \mathrm{c}$ \\
\hline
\end{tabular}

Ghi chú: *Các chữ cái khác nhau $(\mathrm{a}, \mathrm{b} . .$.$) trong cùng một cột biểu thị sự khác biệt có ý nghĩa thống kê ở$ $\alpha=0,05$ (Duncan's test).

Các kết quả thu được sau 6 tuần trồng ngoài vườn ươm ở cây Địa lan cho thấy chiều cao cây, số lá và chiều dài rễ không có sự khác biệt rõ rệt giữa các loại đèn compact và đèn neon, 
điều này chứng tỏ chiều cao cây, số lá và chiều dài rễ không bị ảnh hưởng bởi chất lượng ánh sáng từ các loại đèn khác nhau xử lí trong giai đoạn in vitro. Tuy nhiên, số rễ và chiều cao của cây thu được ở nghiệm thức đèn WU lại cao hơn hẳn so với các loại đèn khác. Kết quả này cũng tương tự như trong giai đoạn ra rễ in vitro cây Địa lan là đèn WU thích hợp nhất cho giai đoạn ra rễ của cây Địa lan (Bảng 3.2).

\section{KẾT LUẬn}

\section{Đối với cây Cúc}

Chất lượng ánh sáng có ảnh hưởng tới quá trình nhân chồi và sự hình thành rễ của cây Cúc. So với đèn neon, đốt thân Cúc đặt dưới các đèn $R U, W U$ và $3 U$ có khả năng tạo nhiều chồi với chất lượng cao, trong đó đèn $3 \mathrm{U}$ cho cây có chất lượng cao nhất.

Chồi Cúc phát triển trong môi trường ra rễ dưới đèn $\mathrm{RU}, \mathrm{WU}$ và $3 \mathrm{U}$ tương đối cao, trong đó đèn WU là thích hợp nhất cho sự ra rễ của Cúc in vitro cũng như khi chuyển ra vườn ươm.

\section{Đối với Địa lan}

Hệ số nhân PLB, khối lượng tươi PLB chịu ảnh hưởng của chất lượng ánh sáng, trong khi đó số chồi tạo thành thì không. Đèn $3 \mathrm{U}$ cho khả năng tạo PLB là cao nhất.

Chất lượng ánh sáng không ảnh hưởng đến sự ra rễ của Địa lan. Tuy nhiên, khi xét về các chỉ tiêu khác (chiều dài lá, chiều rộng lá, khối lượng tươi cây) thì đèn WU cho cây có chất lượng cao nhất nên nó thích hợp để sử dụng trong giai đoạn nuôi cấy ra rễ của Địa lan.

\section{TÀI LIỆU THAM KHẢO}

1. Nhut D. T., Huong M. T. N. - Compact $3 \mathrm{U}$ as a novel artificial lighting source for Gloxinia (Sinningia spp.) and Potato (Solanum tuberosum) micropropagation, Asean J. Sci. Technol. Dev. 23 (2006) 333-341.

2. Bula R. J, Morrow T. W., Tibbitts T. W., Barta D. J., Ignatius R. W., Martin T. S. - Lightemitting diodes as a radiation source for plants, Hort. Sci. 26 (2) (1991) 203-205.

3. Moe R. - Physiologycal aspects of supplementary lighting in horticulture, Acta Hort. 418 (1997) 17-24.

4. Tibbitts T. W., Morgan D. C., Warrington I. J. - Growth of lectuce, spinach, mustard and wheat plants under four combinations of high-pressure sodium, matal halide, and tungsten halogen lamps at equal PPFD, J. Amer. Soc. Hort. Sci. 108 (4) (1983) 622-630.

5. Nhut D. T., Huong M. T. N., Khiem D. V., Teixeira da Silva J. A. - Compact 3U as a novel lighting source for the propagation of some horticultural plants., J. Appl. Hort. 8 (2006) 1520.

6. Murashige T., Skoog F. - A revised medium for rapid growth and bioassays with tobacco tissue cultures, Plant Physiol. 15 (1962) 473-497.

7. Duncan D. B. - Multiple range and multiple F test. Biometrics 11 (1995) 1-42.

8. Moreira da Silva M. H., Degerph P. C. - The effect of light quality on the morphogenesis of in vitro cultures of Azorina vidalii (Wats.) Feer, Plant Cell Tiss. Org. 51 (1997) 187-198. 
9. Mortensen L. M., Stromme E. - Effects of light quality on some greenhouse crops, Hort. Sci. 33 (1987) 27-36.

10. Schuerger A. C., Brown C. S., Stryjewski E. C. - Anatomical features of pepper plants (Capsicum annuum L.) grow under red light-emitting diodes supplemented with blue or farred light, Ann. Bot. 79 (1997) 273-282.

\section{ABSTRACT \\ EFFECT OF ARTIFICIAL LIGHTS ON GROWTH AND DEVELOPMENT OF CYMBIDIUM AND CHRYSANTHEMUM}

Duong Tan Nhut, Le Thi Phuong Thao, Trinh Thi Huong, Nguyen Ba Nam

Tay Nguyen Institute for Scientific Research, Vietnam Academy of Science and Technology

"Email: duongtannnhut@gmail.com

Light is the main energy source in photosynthesis of plants. However, fluorescent light have being used as a major light in lots of plant tissue culture laboratories nowadays. Large amount of electricity is, therefore, consumed leading to high cost of seedlings in commerce. Hence, in this study, we investigated the effects of energy-saving light source (compact fluorescent lamp) on the ability of the growth and development of Chrysanthemum and Cymbidium in order to determine an alternative system of power saving rather than traditional lighting system. Obtained results showed that lamps containing more red lights (1U red compact fluorescent lamp, $1 \mathrm{U}$ white compact fluorescent lamp and $3 \mathrm{U}$ compact fluorescent lamp) were more optimal for the plant development compared to those majoring in blue lights (GU). Among examined lamps, $3 \mathrm{U}$ compact fluorescent lamp was recognized as the best for shoot formation of Chrysanmethum as well as the formation rate of protocorm like body (PLB) and fresh weight of PLB in Cymbidium. On the other hands, $1 \mathrm{U}$ compact fluorescent lamp was the most suitable in term of root formation in both Chrysanmethum and Cymbidium and the development of seedlings growing in the nursery. Thus, instead of traditional lighting system (neon), compact lamps should be considered in utilization due to its enhancement in not only energy-saving but also the growth and development of plants.

Keywords: chrysanthemum, compact, Cymbidium, growth, light. 